\title{
Narrativa
}

\section{Flaviano PISANELLI, Laura TOPPAN, Confini di-versi. Frontiere, orizzonti e prospettive della poesia italofona contemporanea}

\section{Marta Mariani}

\section{OpenEdition}

Journals

\section{Edizione digitale}

URL: https://journals.openedition.org/narrativa/324

DOI: $10.4000 /$ narrativa.324

ISSN: 2804-1224

\section{Editore}

Presses universitaires de Paris Nanterre

\section{Edizione cartacea}

Data di pubblicazione: 1 décembre 2020

Paginazione: 197-198

ISBN: 978-2-84016-381-7

ISSN: 1166-3243

\section{Notizia bibliografica digitale}

Marta Mariani, «Flaviano pISANelLI, Laura toppan, Confini di-versi. Frontiere, orizzonti e prospettive della poesia italofona contemporanea», Narrativa [Online], 42 | 2020, online dal 01 novembre 2021, consultato il 08 décembre 2021. URL: http://journals.openedition.org/narrativa/324 ; DOI: https://doi.org/ 10.4000/narrativa.324

\section{Questo documento è stato generato automaticamente il 8 décembre 2021.}

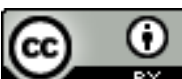

Narrativa est mise à disposition selon les termes de la Licence Creative Commons Attribution 4.0 International. 


\title{
Flaviano PISANELLI, Laura TOPPAN, Confini di-versi. Frontiere, orizzonti e prospettive della poesia italofona contemporanea
}

\author{
Marta Mariani
}

\section{NOTIZIA}

Flaviano PISANELLI, Laura TOPPAN, Confini di-versi. Frontiere, orizzonti e prospettive della poesia italofona contemporanea, Firenze, University Press, 2019, pp. 312.

1 Il volume intende rispondere all'esigenza di offrire agli studiosi del settore un utile strumento critico, ovvero il disegno dei profili individuali di alcuni poeti della migrazione che si esprimono in lingua italiana. A questo scopo gli autori si avvalgono delle acquisizioni inerenti, più genericamente, alle scritture della migrazione. Confini diversi ha il merito di esplorare la scrittura poetica degli autori italofoni in una prospettiva che è insieme estetico-letteraria, storica, sociologica e incline alla considerazione di fatti antropologici. Vengono immediatamente analizzati i principali esiti della globalizzazione e dei processi di massificazione, per adottare una prospettiva pienamente relazionale, grazie alla quale i poeti (esuli, espatriati, spesso plurilingue), pur trovandosi in uno spazio che è "altrove" e "al di là", riescono a mantenere vive e correlate realtà culturali diverse, facendosi vere e proprie "identità-ponte". Dando per necessaria l'uscita dall'ottica ormai obsoleta e improduttiva dell'eurocentrismo per guardare ai nuovi orizzonti dell'auspicata creolizzazione, gli autori si interessano alla scrittura dell'erranza indagando le forme poetiche, cangianti e ibridate, tramite le quali l'interculturalità plasma e modella l'immaginario (un tertium, o meglio, un mosaico transnazionale che non è la semplice congiunzione tra una cultura di partenza e una cultura di approdo). Le "identità diasporiche" chiamano in causa il concetto di 
"traduzione" usato da Salman Rushdie: "Essendo stati trasportati al di là dell'oceano, noi siamo uomini tradotti" (p. 25). Queste identità vengono problematizzate dagli autori non tanto in una prospettiva di affermazione (tipica della dialettica tra colonizzazione e decolonizzazione) quanto in quella di differimento, affinché sia possibile "evidenziare le differenze che ciascuna identità esprime all'altra" (p. 25). Le pregevoli interviste ai poeti, oltre a porre al centro della riflessione dialogica le nozioni di lingua e di traduzione, mettono in luce le peculiarità dell'italofonia. L'italiano, presentandosi solo debolmente come lingua di tradizione coloniale, è adottato volentieri dai poeti migranti come codice veicolante. Tali considerazioni portano dunque gli autori ad interrogarsi sia sul valore letterario delle produzioni poetiche italofone contemporanee, sia sulle eventuali zone di osmosi tra queste ultime e l'orizzonte della tradizione letteraria italiana. Si apre infine alla possibilità di scandagliare quegli elementi di raccordo che potrebbero legare la letteratura italofona contemporanea alle voci poetanti della diaspora che cantano nelle altre lingue europee. 